\title{
$\mathbf{R}$

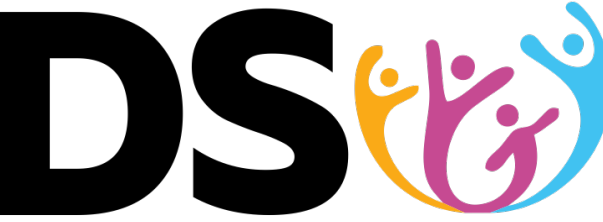

Revista Desenvolvimento Social

\section{ANÁLISE DOS INDICADORES DE DESENVOLVIMENTO RURAL DO NORTE DE MINAS}

\author{
Claudiana Aparecida Leal de Araujo ${ }^{1}$ \\ Carlos Renato Theóphilo²
}

Resumo: A noção de desenvolvimento rural está ligada a transformações, a melhoria da qualidade de vida da população rural, considerando os aspectos plurais existentes nesse meio. O desenvolvimento rural, de certa forma, resulta de ações articuladas nas vertentes cultural, social e econômica com o objetivo de melhorar qualidade de vida no espaço rural. O objetivo deste trabalho foi de analisar os níveis de desenvolvimento rural dos municípios da Mesorregião Norte de Minas, com base nos indicadores populacionais, de bem-estar social, econômicos e ambientais no ano de 2010. A metodologia utilizada foi baseada no estudo de Kageyama (2004), que adotou o Índice de Desenvolvimento Rural (IDR), um índice composto, obtido pela média de outros indicadores, a saber: os indicadores de população, de bem-estar social, desenvolvimento econômico e meio ambiente. A ideia de medir o desenvolvimento rural por meio de um indicador possibilitou uma reflexão sobre uma medida que resultasse da combinação de diversas dimensões importantes nesse contexto. A análise do IDR reforçou a ideia de que os aspectos multidimensionais são fundamentais para o desenvolvimento rural. Além disso, medir o desenvolvimento rural exige escolha criteriosa de variáveis e a combinação dessas em cada dimensão, além da observação das características da região a ser analisada.

Palavras-chave: Desenvolvimento Rural; Índice de Desenvolvimento Rural.

\section{ANALYSIS OF INDICATORS FOR RURAL DEVELOPMENT IN THE NORTH OF MINAS GERAIS}

Abstract: The notion of rural development is linked to transformations, the improvement of the quality of life of the rural population, considering the plural aspects that exist in this environment. Rural development, in a way, results from actions articulated in the cultural, social and economic aspects with the objective of improving the quality of life in rural areas. The objective of this work was to analyze the levels of rural development in the municipalities of the North Mesoregion of Minas, based on population, social, economic and environmental wellbeing indicators in 2010. The methodology used was based on the study by Kageyama (2004), which adopted the Rural Development Index (RDI), a composite index, obtained by averaging other indicators, namely: population, social well-being, economic development and environment indicators. The idea of measuring rural development through an indicator made it possible to reflect on a measure that resulted from the combination of several important dimensions in this context. The IDR analysis reinforced the idea that multidimensional aspects

\footnotetext{
1 Mestre em Desenvolvimento social pela Universidade Estadual de Montes Claros (Unimontes), Professora-pesquisadora da Unimontes. E-mail claudiana.araujo@unimontes.br. ORCID https://orcid.org/0000-0002-6387-9484.

2 Mestre e Doutor em Controladoria e Contabilidade pela Faculdade de Economia, Administração e Contabilidade da Universidade de São Paulo (FEA/USP). Professor-pesquisador da Universidade Estadual de Montes Claros - UNIMONTES. E-mail: crtheophilo@uol.com.br. https://orcid.org/0000-0002-28573287.
} 
are fundamental to rural development. Furthermore, measuring rural development requires a careful choice of variables and the combination of these in each dimension, in addition to observing the characteristics of the region to be analyzed.

Keywords: Rural Development; Rural Development Index.

\section{ANÁLISIS DE INDICADORES DE DESARROLLO RURAL DEL NORTE DE MINAS}

Resumen: La noción de desarrollo rural está vinculada a las transformaciones, la mejora de la calidad de vida de la población rural, considerando los aspectos plurales que existen en este entorno. El desarrollo rural, en cierto modo, resulta de acciones articuladas en los aspectos culturales, sociales y económicos con el objetivo de mejorar la calidad de vida en las zonas rurales. El objetivo de este trabajo fue analizar los niveles de desarrollo rural en los municipios de la Mesorregión Norte de Minas, con base en indicadores poblacionales, sociales, económicos y de bienestar ambiental en 2010. La metodología utilizada se basó en el estudio de Kageyama (2004), que adoptó el Índice de Desarrollo Rural (IDR), un índice compuesto, obtenido promediando otros indicadores, a saber: población, bienestar social, desarrollo económico y medio ambiente. La idea de medir el desarrollo rural a través de un indicador permitió reflexionar sobre una medida que resultó de la combinación de varias dimensiones importantes en este contexto. El análisis del IDR reforzó la idea de que los aspectos multidimensionales son fundamentales para el desarrollo rural. Además, la medición del desarrollo rural requiere una cuidadosa elección de variables y la combinación de estas en cada dimensión, además de observar las características de la región a analizar.

Palabras clave: Desarrollo Rural; Índice de Desarrollo Rural.

\section{INTRODUÇÃO}

A concepção de desenvolvimento está ligada à transformação social, à busca pelo bem-estar, pela melhoria nas condições de vida, pela construção de valores. Conceituá-lo ainda é considerada uma discussão complexa e vem incorporando novas dimensões, novas adjetivações, que se relacionam entre si, sendo identificada com a ideia de liberdade do ser humano, na concepção de Sen (2010).

Existe um esforço no sentido de buscar uma medida que mensure ou avalie o desenvolvimento, não se limitando ao aspecto econômico. Essa busca envolve a discussão e a construção de indicadores sociais que possam ser utilizados como ferramentas de medidas do desenvolvimento. Embora, se admita, dificilmente haverá um indicador que reflita a totalidade de questões de um determinado segmento, especialmente, no espaço rural onde está presente um conjunto de singularidades relativas ao modo de vida, aos aspectos ambientais, econômicos, sociais, que se articulam de formas diferentes em cada região.

A discussão sobre desenvolvimento rural foi precedida com o debate sobre a questão agrária que surgiu a partir de uma ação intelectual e política pro-camponesa. 
As perspectivas teóricas representaram um papel fundamental na implementação do Desenvolvimento Rural, foram: Desenvolvimento comunitário: considerado a perspectiva da teoria sociológica da vida rural, está associada à necessidade de introduzir, no manejo dos recursos naturais, as tecnologias derivadas das ciências agropecuárias e florestais; Desenvolvimento rural integrado: considerado sob a perspectiva da teoria da modernização, está ligado à necessidade de industrializar a agricultura. Essa teoria, geralmente, transforma os camponeses e agricultores em empresários, a partir da introdução de mudanças tecnológicas; e Desenvolvimento rural sustentável: considerado sob a perspectiva da teoria da sustentabilidade, estando relacionada ao ecodesenvolvimento ${ }^{3}$, à adoção de ações com viés da preservação ambiental.

Tendo presente esse entendimento, Kageyama (2004) idealizou o que denominou de Índice de Desenvolvimento Rural (IDR), obtido pela média de outros indicadores, de: população, bem-estar social, desenvolvimento econômico e meio ambiente. Esse indicador tem por objetivo mensurar o desenvolvimento rural levandose em conta alguns aspectos mais importantes contidos na multisetorialidade do espaço rural.

O interesse deste estudo se voltou para a busca de mensuração do desenvolvimento rural. Como recorte geográfico, escolheu-se analisar a Mesorregião Norte de Minas, por ser entre as regiões de Minas Gerais a de maior participação da agricultura familiar no conjunto populacional do Estado, cujos indicadores econômicos se assemelham aos da região Nordeste do Brasil (IBGE, 2010). A escolha do ano de 2010 se justifica por ser o ano do Censo mais recente, com publicação de dados que abrangem todos os aspectos envolvidos na pesquisa.

Considerando o contexto, o presente estudo tem como questão norteadora: Qual o nível de desenvolvimento rural - com base em indicadores populacionais, de bem-estar social, econômicos e ambientais - dos municípios da Mesorregião Norte de Minas, no ano de 2010?

O objetivo geral deste trabalho é analisar o nível de desenvolvimento rural dos municípios da Mesorregião Norte de Minas, com base nos indicadores populacionais, de

\footnotetext{
3 Os conceitos de "Ecodesenvolvimento" e "Desenvolvimento Sustentável" são sinônimos, com cinco dimensões de sustentabilidade: social, econômica, ecológica, espacial e cultural (SACHS, 1993).
} 
bem-estar social, econômicos e ambientais, no ano de 2010. Especificamente, busca-se: a) Calcular o Índice de Desenvolvimento Rural para os municípios da Macrorregião Norte de Minas, no ano de 2010; b) Analisar os níveis de desenvolvimento apresentados pelos municípios da Mesorregião.

Este estudo ganha relevância por analisar os objetivos propostos, contribuindo para a discussão sobre desenvolvimento, além de buscar uma forma de medir os níveis de desenvolvimento rural dos municípios do Norte de Minas. Para calcular o Índice de Desenvolvimento Rural são utilizados dados relativos à população rural divulgados no Censo Demográfico 2010 e no Censo Agropecuário de $2006^{4}$, partindo da avaliação de alguns indicadores, considerando os aspectos econômicos, sociais, de bem-estar e ambientais da região pesquisada.

Para definição do Índice de Desenvolvimento Rural (IDR), adotou-se a metodologia baseada no modelo sugerido nos estudos de Kageyama (2004). Outros estudos, como os de Melo (2005) e Silva (2006) foram realizados posteriormente a esse, adaptando-se as variáveis aos objetivos propostos pelos pesquisadores. Para este estudo, após a análise crítica das variáveis utilizadas nos estudos anteriores, foram escolhidas as que, entendeu-se, melhor expressam essa medida segundo os objetivos propostos, para a mesorregião pesquisada. Assim, este índice deve ser compreendido como resultado da ponderação dessas variáveis, também sujeitas a futuras adaptações.

Em termos da estruturação, o artigo discute as concepções de desenvolvimento e suas adjetivações. Em seguida, apresenta discussão acerca dos indicadores de desenvolvimento social e do Índice de Desenvolvimento Rural. E por fim expõe a análise sobre os indicadores e os níveis de desenvolvimento rural dos municípios da Mesorregião Norte de Minas, no ano 2010; e as principais considerações acerca do desenvolvimento rural no Norte de Minas.

\section{ABORDAGENS SOBRE DESENVOLVIMENTO RURAL}

A discussão sobre desenvolvimento rural foi precedida com o debate sobre a questão agrária, que surgiu a partir de uma ação intelectual e política pró-camponesa.

\footnotetext{
${ }^{4}$ Censo Agropecuário com dados publicados no período da pesquisa.
} 
Neste sentido, as perspectivas teóricas representaram um papel fundamental na implementação do desenvolvimento rural, sendo agrupadas, por Guzman (2005), em três categorias, conforme descritas a seguir. Desenvolvimento comunitário: considerada a perspectiva da teoria sociológica da vida rural, está associada à necessidade de introduzir, no manejo dos recursos naturais, as tecnologias derivadas das ciências agropecuárias e florestais; Desenvolvimento rural integrado: considerado sob a perspectiva da teoria da modernização, está ligada à necessidade de industrializar a agricultura, essa teoria, geralmente, transforma os camponeses e agricultores em empresários, a partir da introdução de mudanças tecnológicas; e Desenvolvimento rural sustentável: considerado sob a perspectiva da teoria da sustentabilidade, estando relacionada ao ecodesenvolvimento, à adoção de ações com viés da preservação ambiental.

Segundo Saborin (2009), a experiência do Norte e Nordeste brasileiro quanto ao desenvolvimento rural sustentável nasce das agências multilaterais e das organizações da sociedade civil ligadas a agricultores, e é caracterizada por três processos que interatuam entre si: a) a atuação do Estado, desarticulada em diversos apoios à produção (comercialização, extensão, formação), especialmente no que diz respeito à agricultura familiar; b) implementação de políticas públicas para agricultura familiar, a partir de uma ideia social e assistencialista; c) ênfase no aspecto territorial e participativo no processo de desenvolvimento.

Pensar o desenvolvimento para as regiões rurais deve-se considerar as especificidades e os fatores que determinam sua dinâmica territorial, nas vertentes cultural, social e econômica. Tendo em vista que o meio rural tem um papel preponderante no desenvolvimento contemporâneo, para o qual foi dada uma especial atenção nos últimos anos. Nas palavras de Schneider (2004, p. 98-99), "desenvolvimento rural é definido como um processo que resulta de ações articuladas, que visam induzir mudanças socioeconômicas e ambientais no âmbito do espaço rural para melhorar a renda, a qualidade de vida e o bem-estar das populações rurais".

Atualmente no Brasil, está mais difícil diferenciar o urbano e o rural. Percebe-se uma urbanização do rural como resultado do processo de industrialização e do inchamento do mundo urbano, no espaço definido como rural. Nessa mudança, há uma integração entre o urbano e o rural na economia, a agricultura deixa de ser apenas 
fornecedora de insumos, passando também a comprar. O resultado dessa integração foi a consolidação dos "complexos agro-industriais" que respondem pela dinâmica das atividades a ela vinculadas (SILVA, 1997).

Neste sentido, é que surge a noção de "sistema econômico local", não se limitando essa concepção ao isolamento, mas à "abertura de novas oportunidades com base no aperfeiçoamento do tecido institucional de cada região" (ABRAMOWAY, 2003, p. 91). Diante disso, o autor, enfatiza como desafios a falta de estudos que propiciem o estabelecimento de tipologias acerca do alcance e limites da atuação das organizações para o desenvolvimento rural. Entretanto, apresenta algumas hipóteses que buscam facilitar a superação das principais dificuldades: a necessidade de associação de trabalho ao conhecimento, o que implica em mudança no ambiente educacional; a formação de uma rede de atores que busquem a valorização dos atributos de certa região; reconhecimento da insuficiência da esfera política e administrativa necessária para gerir o desenvolvimento local; organização de iniciativas que materializem a existência da dinâmica territorial; criação de novos mercados que ponham em destaque as capacidades regionais "territorializadas"; colaboração de faculdades e universidades na formação de redes de desenvolvimento territorial; construção de uma nova visão do meio rural (ABRAMOWAY, 2003).

\section{INDICADORES DE DESENVOLVIMENTO RURAL}

Os indicadores são caracterizados por diferentes adjetivos: econômicos, sociais, gerenciais, de desempenho, de qualidade, dentre outros. Fato que depende do aspecto e da metodologia de avaliação. Um indicador é uma ferramenta que possibilita mensurar aspectos de um determinado conceito, realidade, fenômeno ou um problema, e seu objetivo principal é "[...] traduzir de forma mensurável determinado aspecto de uma realidade dada (situação social) ou construída (ação de governo)" (BRASIL, 2010, p. 16).

É importante distinguir indicadores sociais de estatísticas públicas. Indicadores servem para subsidiar as atividades de planejamento público e formulação de políticas públicas, possibilitando um monitoramento e avaliação das condições de vida e bemestar da população, enquanto as estatísticas correspondem a um dado social, não 
contextualizado numa teoria social, estando disponível para interpretação empírica da realidade. Estas são levantadas nos Censos Demográficos, pesquisas amostrais coletadas pelos Ministérios, Secretarias de Estado e Prefeituras (JANNUZZI, 2012).

Kageyama (2004) destaca que o Programa de Desenvolvimento Rural da OCDE, lançado em 1991, enumera três etapas para a elaboração de indicadores de desenvolvimento rural. Primeiro, estabeleceu um esquema territorial que permitiu classificar as regiões em três tipos: predominantemente rurais, predominantemente urbanizadas e significativamente rurais. A densidade populacional é o indicador básico que determina os territórios em rurais e urbanos. Segundo, são definidos os indicadores demográficos, econômicos, sociais e ambientais. Terceiro, são produzidas as estatísticas que possibilitam a análise e comparação das disposições do desenvolvimento rural.

Segundo Kageyama (2004), analisar todos esses indicadores em níveis regionais só é possível se o pesquisador fizer um grande esforço, pois estando limitado às estatísticas disponíveis (coletadas para outros fins) seria impossível a reprodução dessas medidas para todas as unidades territoriais.

O resultado apresentado em um Indicador de Desenvolvimento Rural deve refletir diferentes aspectos. Nesse caso, dificilmente haverá um indicador que reflita a totalidade de questões do segmento, dependendo inclusive dos objetivos das políticas públicas implementadas e do estudo realizado. O IDR, proposto, é um indicador composto, obtido pela média de outros indicadores sobre a população, o bem-estar social, o desenvolvimento econômico e o meio ambiente. Esse indicador busca contemplar alguns aspectos mais importantes contidos na multisetorialidade do espaço rural (KAGEYAMA, 2004). Ainda que se faça o esforço de elaboração do indicador, pela importância de se buscar medidas de avaliação do desenvolvimento rural, admite-se a limitação de deixar de considerar possíveis variáveis relevantes, seja pela dificuldade de dados que a expressem, seja pela sua não identificação.

O presente trabalho partiu do modelo sugerido por Kageyama (2004), o qual levou em conta o conjunto básico de indicadores sugeridos pela OCDE. Foi realizada uma detalhada análise crítica desse modelo, o que levou à sua adaptação, seja pela inclusão de novas variáveis, seja pela revisão das medidas de outras variáveis. Para cálculo do Indicador de Desenvolvimento Rural (IDR), inicialmente foram computados quatro 
indicadores parciais, compostos pela média aritmética de indicadores simples, os quais são descritos na Quadro 1:

\section{Quadro 1 - Indicadores selecionados para caracterização dos municípios - Índice de Desenvolvimento Rural (IDR)}

\begin{tabular}{|c|c|c|c|}
\hline Indicador & Descrição da Variável & Cálculo & Base de dados \\
\hline \multirow{3}{*}{$\begin{array}{l}\text { Indicador de } \\
\text { População } \\
\text { IPOP }=(a+b+c) / 3\end{array}$} & $\begin{array}{l}\text { a) Variação da População } \\
\text { Rural }\end{array}$ & $\begin{array}{l}\text { Diferença entre a população rural } \\
\text { nos anos de } 2010 \text { e } 2001 \text { / } \\
\text { População rural de } 2001\end{array}$ & $\begin{array}{l}\text { IBGE - Censo } \\
\text { Demográfico } \\
\text { 2001/2010 }\end{array}$ \\
\hline & $\begin{array}{l}\text { b) Proporção da } \\
\text { população } \\
\text { rural do município }\end{array}$ & $\begin{array}{l}\text { População rural / População Total } \\
\text { do município }\end{array}$ & $\begin{array}{l}\text { IBGE - Censo } \\
\text { Demográfico } \\
2010\end{array}$ \\
\hline & $\begin{array}{l}\text { c) Proporção da } \\
\text { População rural que } \\
\text { mora no município há } \\
\text { menos de } 10 \text { anos } \\
\text { (migração) }\end{array}$ & $\begin{array}{l}\text { População rural que mora no } \\
\text { município há menos de } 10 \text { anos / } \\
\text { população rural do município }\end{array}$ & $\begin{array}{l}\text { IBGE - Censo } \\
\text { Demográfico } \\
2010\end{array}$ \\
\hline \multirow{4}{*}{$\begin{array}{l}\text { Indicador de Bem- } \\
\quad \text { estar Social } \\
\text { IBES }=(d+e+f+g) / 4\end{array}$} & $\begin{array}{l}\text { d) Percentual de } \\
\text { Alfabetização da } \\
\text { População - } 15 \text { anos ou } \\
\text { mais }\end{array}$ & $\begin{array}{l}\text { População rural com } 15 \text { anos ou } \\
\text { mais alfabetizada / População Rural } \\
\text { Total }\end{array}$ & $\begin{array}{l}\text { IBGE - Censo } \\
\text { Demográfico } \\
2010\end{array}$ \\
\hline & $\begin{array}{l}\text { e) Proporção de } \\
\text { domicílios rurais com } \\
\text { acesso a água }\end{array}$ & $\begin{array}{l}\text { Total dos domicílios rurais com } \\
\text { acesso à água / Total dos domicílios } \\
\text { rurais }\end{array}$ & $\begin{array}{l}\text { IBGE - Censo } \\
\text { Demográfico } \\
2010\end{array}$ \\
\hline & $\begin{array}{l}\text { f) Proporção de } \\
\text { domicílios rurais com } \\
\text { banheiro }\end{array}$ & $\begin{array}{l}\text { Total de domicílios rurais com } \\
\text { banheiro/Total de domicílios rurais }\end{array}$ & $\begin{array}{l}\text { IBGE - Censo } \\
\text { Demográfico } \\
2010\end{array}$ \\
\hline & $\begin{array}{l}\text { g) Proporção de } \\
\text { domicílios rurais com } \\
\text { energia elétrica }\end{array}$ & $\begin{array}{l}\text { Total dos domicílios rurais com } \\
\text { energia elétrica/Total dos } \\
\text { domicílios rurais }\end{array}$ & $\begin{array}{l}\text { IBGE - Censo } \\
\text { Demográfico } \\
2010\end{array}$ \\
\hline \multirow{4}{*}{$\begin{array}{l}\text { Indicador de } \\
\text { Desenvolvimento } \\
\text { Econômico } \\
\text { IDE }=(h+i+j+k) / 4\end{array}$} & $\begin{array}{l}\text { h) Produtividade } \\
\text { Agropecuária }\end{array}$ & $\begin{array}{l}\text { Valor da produção agropecuária / } \\
\text { Valor do PIB do município }\end{array}$ & $\begin{array}{l}\text { IBGE - Censo } \\
\text { Demográfico } \\
2010\end{array}$ \\
\hline & $\begin{array}{l}\text { i) Proporção de ocupados } \\
\text { na área rural }\end{array}$ & $\begin{array}{l}\text { Pessoas ocupadas (10 anos ou } \\
\text { mais) nos domicílios rurais/Total de } \\
\text { Pessoas ocupadas do município }\end{array}$ & $\begin{array}{l}\text { IBGE - Censo } \\
\text { Demográfico } \\
2010\end{array}$ \\
\hline & $\begin{array}{l}\text { j) Renda per capita rural } \\
\text { (média) }\end{array}$ & $\begin{array}{l}\text { Renda per capita rural } \\
\text { /Rendimento Médio per capita do } \\
\text { município }\end{array}$ & $\begin{array}{l}\text { IBGE - Censo } \\
\text { Demográfico } \\
2010\end{array}$ \\
\hline & $\begin{array}{l}\text { k) Percentual de receita } \\
\text { de atividades não } \\
\text { agropecuárias }\end{array}$ & $\begin{array}{l}\text { Receitas do estabelecimento rural } \\
\text { provenientes de atividades não } \\
\text { agropecuárias/Receita total do } \\
\text { domicílio rural }\end{array}$ & $\begin{array}{l}\text { IBGE - Censo } \\
\text { Agropecuário } \\
2006\end{array}$ \\
\hline $\begin{array}{l}\text { Indicador de Meio } \\
\qquad \text { Ambiente } \\
\mathrm{IMA}=(1+\mathrm{m}+\mathrm{n}) / 3\end{array}$ & $\begin{array}{l}\text { l) Proporção de } \\
\text { estabelecimentos que } \\
\text { adotam prática de } \\
\text { conservação do solo }\end{array}$ & $\begin{array}{l}\text { Número de estabelecimentos } \\
\text { agropecuários que adotam prática } \\
\text { de conservação do solo / Número }\end{array}$ & $\begin{array}{l}\text { IBGE - Censo } \\
\text { Agropecuário } \\
2006\end{array}$ \\
\hline
\end{tabular}




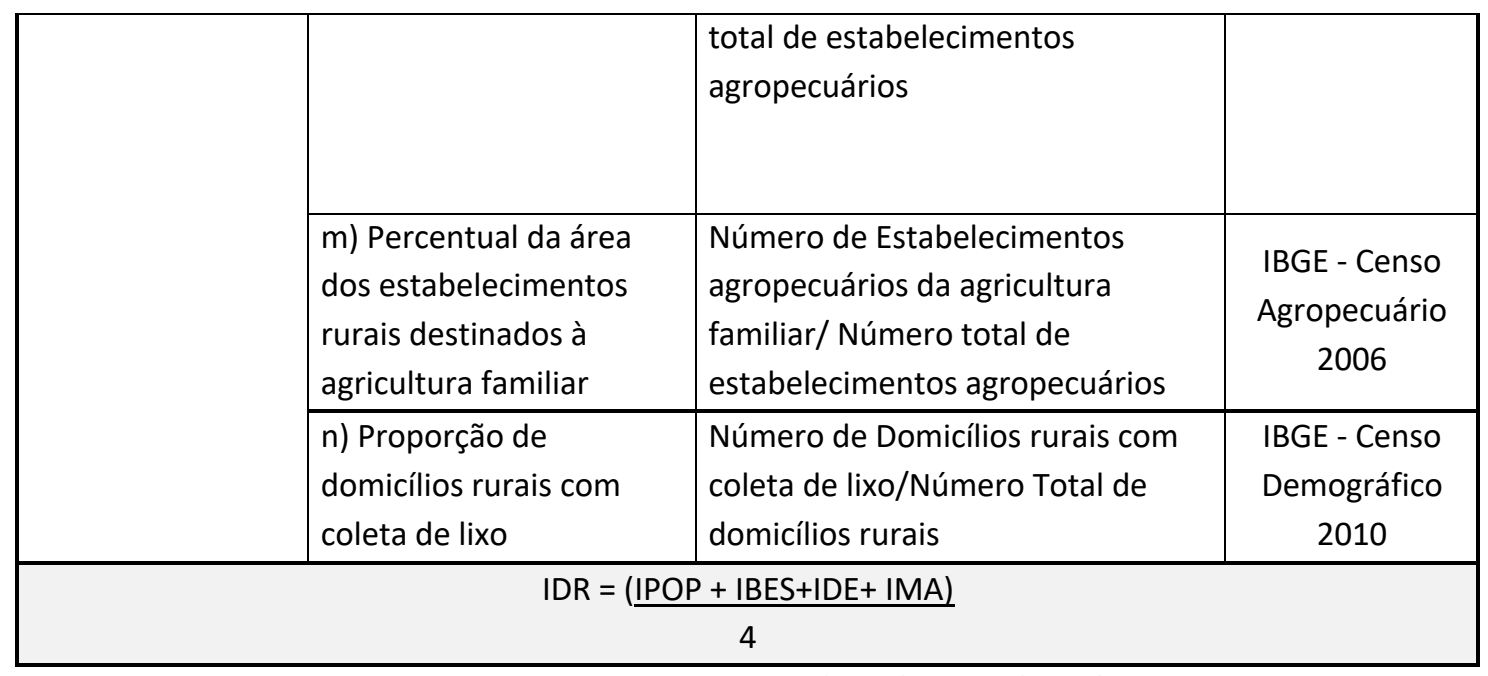

Fonte: Adaptado de Kageyama (2004) e Silva (2006)

O indicador de População (IPOP) busca medir o aspecto populacional do município, ou seja, a ideia essencial desse indicador é de que, quanto mais alto o nível de Desenvolvimento Rural, maior o favorecimento ao dinamismo populacional ${ }^{5}$. 0 segundo indicador é o de Bem-Estar Social (IBES), o qual inclui indicadores que visam levantar aspectos referentes à educação (taxa de alfabetização) e os indicadores relevantes para levantar as condições de infraestrutura do domicílio. Outros indicadores poderiam ser selecionados, no entanto optou-se por aqueles que abrangem as necessidades básicas para o bem-estar da população, elevando assim o desenvolvimento rural. O terceiro grupo, Indicadores de Desenvolvimento Econômico (IDE), foca o perfil de ocupação, do rendimento médio dos domicílios, bem como a produtividade agropecuária e receitas dos domićlios. Quanto maior esse indicador, maior o IDR. Nesse Indicador IDE, algumas ponderações devem ser mencionadas. Primeiro, que a renda per capita pode não considerar as necessidades individuais e específicas de cada indivíduo, em termos de consumo (alimentação, vestuário), lazer, dentre outros. Além disso, outro ponto importante é a dificuldade de mensurar os rendimentos não monetários, principalmente no universo dos grupos de agricultores familiares, nos quais a produção, muitas vezes, está ligada ao próprio consumo. No que se refere ao Indicador de Meio-ambiente (IMA), o objetivo é destacar variáveis relevantes para o Desenvolvimento Rural, no âmbito das questões envolvendo a preservação do meio-ambiente.

\footnotetext{
${ }^{5}$ Entende-se por dinamismo populacional as características referentes aos movimentos migratórios e ao crescimento da população no período.
} 


\section{O NORTE DE MINAS}

A Mesorregião Norte de Minas, está localizada na Região Sudeste e é formada por 89 municípios. Seus indicadores econômicos são semelhantes aos da Região Nordeste, sendo que o desenvolvimento da economia baseou-se na agricultura de subsistência ${ }^{6}$ e na pecuária bovina (RODRIGUES, 2000).

Segundo Carvalho (2012, p. 20), apesar de ser uma região com certo "atraso econômico", o Norte de Minas é uma região caracterizada por uma diversidade agrícola e pecuária que consiste no cultivo de lavouras de milho, cana, feijão, hortaliças, café, dentre outras e também, na criação de gado, aves e suínos, além das atividades extrativistas ${ }^{7}$ que resultam na produção de mel, lenha, frutos do cerrado e plantas medicinais (SILVA et al, 2009). Também estão presentes na mesorregião ${ }^{8}$ as atividades descritas como modernizadoras, com avanço do agronegócio sobre os recursos naturais que geram os conflitos socioambientais, dentre as quais, "a monocultura de eucalipto é o principal vetor de disputas e conflitos por terra e água" (BRITO, 2012, p. 4). A implantação de áreas de monocultura e de empresas mineradoras ${ }^{9}$ são consideradas como ameaças degradantes aos territórios.

Na acepção discutida por Veiga (2001), em que municípios com menos de 20 mil habitantes seriam rurais, 77,52\% dos municípios da Mesorregião Norte de Minas seriam considerados rurais. Analisando pelo segundo aspecto, em que se consideram rurais os municípios com população menor que 50 mil habitantes, esse percentual aumenta para 94,38\%. Seguindo essa lógica, a grande maioria dos municípios da Mesorregião Norte de Minas, objeto desse estudo, seriam considerados rurais. Em outras palavras, apenas 5 dos 89 municípios analisados, seriam urbanos. No entanto, para este estudo foi

\footnotetext{
${ }^{6}$ Cultivos de arroz, feijão, mandioca, milho, cana de açúcar, algodão e extração de borracha.

${ }^{7}$ As atividades extrativistas realizadas são: a coleta e a produção de óleo de pequi, a coleta da mangaba, de panã, do coquinho azedo para o consumo da própria família e também para a comercialização (SILVA et al, 2009).

${ }^{8}$ Esta região, considerada fronteira de expansão do agronegócio, possui atributos naturais que, na atual conjuntura, são recursos estratégicos que despertam os mais variados interesses: água, terra cultivável, vasta flora medicinal e minerais em abundância (BRITO, 2012, p.5).

9 Refere-se à descoberta de uma mineradora, em 2008, no município de Rio Pardo de Minas (Ver Brito, 2012).
} 
considerado o critério de delimitações dos domicílios rurais e urbanos do IBGE, segundo o qual a área urbana é a área interna ao perímetro urbano de uma cidade ou vila, definida por lei municipal e área rural a área de um município externa ao limite do perímetro urbano (CENSO, 2010).

No Estado de Minas Gerais existem 551.621 estabelecimentos agropecuários, sendo que destes, 437.321 unidades são de agricultura familiar, o que equivale a 79,28\%. Enquanto a área ocupada pela agricultura familiar em Minas (8.845.883 Hectares) corresponde a apenas $26,71 \%$ da área total destinada à agropecuária, no Norte de Minas, os estabelecimentos agropecuários somam um total de 91.163 unidades e ocupam uma área de 5.937.500 Hectares. A presença da agricultura familiar está em 77.717 estabelecimentos, o que equivale a 85,24 \% do total e ocupa apenas 1.754.232 Hectares, ou $29,26 \%$ da área da agropecuária da região. Isso implica em uma média de 22,5 hectares por estabelecimento familiar, e 311,12 hectares de média dos estabelecimentos não familiares.

Esses dados demonstram a distorção entre a área ocupada e o número de estabelecimentos da agricultura familiar, no Estado e particularmente no Norte de Minas, onde o percentual de estabelecimentos de agricultura familiar é $85,24 \%$ e ocupam somente $29,26 \%$ das terras disponíveis, que se assemelha a situação geral do país. Nessa região, a agricultura familiar representa uma proporção maior de estabelecimentos em relação aos dados do Estado, porém, ao maior número de estabelecimentos de agricultura familiar na mesorregião não corresponde uma maior proporção de extensão de terras a ela destinada. Segundo dados do Censo (2006) a agropecuária do Norte de Minas é diversificada, havendo pecuária de corte extensivo, de leite e agricultura de subsistência, sendo que esta é a atividade predominante dos agricultores familiares.

\section{ANÁLISE DO IDR DA MESORREGIÃO NORTE DE MINAS}

Considera-se a premissa de que o índice tem como base o desenvolvimento rural e que este ocorre não somente no aspecto econômico ou de infra-estrutura, ou mesmo, na melhoria da agricultura, mas contemplando simultaneamente essas diversas dimensões. A ideia é de adotar um modelo que busca medir o Desenvolvimento Rural 
com base nesses indicadores que permitirá classificar os níveis de desenvolvimento rural dos municípios da Mesorregião Norte de Minas como de alto, médio e baixo.

Na Tabela 1 são demonstradas as estatísticas descritivas do IDR e seus componentes para o conjunto de municípios estudados. As dispersões mais elevadas são apresentadas nos indicadores parciais de população (IPOP) e de meio ambiente (IMA), evidenciadas pelo elevado coeficiente de variação.

Tabela 1 - Descrição do IDR e seus componentes

\begin{tabular}{l|l|l|l|l|l}
\hline Índices & $\begin{array}{l}\text { Valor } \\
\text { Máximo }\end{array}$ & $\begin{array}{l}\text { Valor } \\
\text { Mínimo }\end{array}$ & Média & $\begin{array}{l}\text { Desvio } \\
\text { Padrão }\end{array}$ & $\begin{array}{l}\text { Coeficiente de } \\
\text { Variação }\end{array}$ \\
\hline IPOP & 0,32 & $-0,12$ & 0,14 & 0,08661 & 0,63445 \\
\hline IBES & 0,83 & 0,47 & 0,68 & 0,07568 & 0,11059 \\
\hline IDE & 0,62 & 0,30 & 0,43 & 0,06988 & 0,16431 \\
\hline IMA & 0,54 & 0,08 & 0,29 & 0,10605 & 0,36306 \\
\hline IDR & 0,47 & 0,29 & 0,38 & 0,04543 & 0,11814 \\
\hline
\end{tabular}

Fonte: Elaboração própria, com base no Censo Agropecuário 2006 e Censo Demográfico 2010

As altas dispersões desses indicadores parciais fariam com que esses tivessem maior peso no cálculo do IDR. Para evitar essa maior influência, os valores dos indicadores parciais foram expressos em números de desvios padrão ${ }^{10}$.

Os níveis de Desenvolvimento Rural dos municípios foram classificados conforme Tabela 2, a seguir:

Tabela 2 - Níveis de Desenvolvimento Rural conforme IDR

\begin{tabular}{l|l}
\hline IDR Baixo & $\leq$ primeiro quartil $(4,47)$ \\
\hline IDR Médio & primeiro quartil $(4,47)<$ IDR $<$ terceiro quartil $(5,24)$ \\
\hline IDR Alto & $\geq$ terceiro quartil $(5,24)$ \\
\hline
\end{tabular}

Com essa classificação, tem-se em cada extremidade $25 \%$ dos municípios e na faixa intermediária 50\%. Ao analisar a distribuição da população rural em vista da classificação dos municípios segundo o nível de IDR, nota-se que $21,67 \%$ vivem em municípios com alto nível de IDR, 49,51 \% com médio IDR, e 28,82 \% com baixo nível de

\footnotetext{
${ }^{10}$ Antes de calcular o valor do IDR, os indicadores parciais foram modificados para variáveis reduzidas, fazendo com que sejam tratados de forma relativa. Para isso, os valores foram divididos pelo desvio padrão.
} 
desenvolvimento rural. A Tabela 3 descreve uma síntese do quantitativo de municípios e da população em cada nível de IDR.

Tabela 3 - Número de municípios e população rural segundo nível de IDR

\begin{tabular}{l|c|c|c}
\hline \multicolumn{1}{c|}{ Nível IDR } & $\begin{array}{c}\text { No de } \\
\text { Municípios }\end{array}$ & Pop. Rural & \% População \\
\hline Baixo IDR & 23 & 141.806 & 28,82 \\
\hline Médio IDR & 43 & 243.672 & 49,51 \\
\hline Alto IDR & 23 & 106.641 & 21,67 \\
\hline Total & 89 & 492119 & 100,00 \\
\hline
\end{tabular}

Fonte: Elaboração própria, com base no Censo Agropecuário 2006 e Censo Demográfico 2010

Nas tabelas a seguir, são analisados cada nível de desenvolvimento em que os municípios da Mesorregião foram agrupados.

A Tabela 4 demonstra a análise descritiva dos índices dos Municípios com Alto IDR.

Tabela 4 - Análise descritiva dos Municípios com Alto IDR

\begin{tabular}{l|l|l|l|l|l}
\hline & IPOP & IBES & IDE & IMA & IDR \\
\hline Valor Máximo & 3,17 & 11,01 & 8,81 & 5,10 & 5,98 \\
\hline Valor Mínimo & 0,52 & 7,93 & 5,17 & 1,95 & 5,23 \\
\hline Média & 2,03 & 9,63 & 6,79 & 3,64 & 5,52 \\
\hline Desvio Padrão & 0,69 & 0,85 & 1,05 & 0,89 & 0,23 \\
\hline Coef. Variação & 0,34 & 0,09 & 0,15 & 0,24 & 0,04 \\
\hline
\end{tabular}

Fonte: Elaboração própria, com base no Censo Agropecuário 2006 e Censo Demográfico 2010

A análise dos municípios com alto IDR indica que não houve predominância da influência de um dos indicadores parciais na sua composição. Para os três melhores IDR, os indicadores parciais que mais contribuíram para essa classificação foram: bem-estar social e de meio ambiente. Destaca-se dois municípios que apresentaram melhor IDR. O município de Gameleiras, com $72,50 \%$ de sua população na área rural, atingiu o melhor IDR na Mesorregião Norte de Minas $(5,98)$. Nota-se que o município ficou acima da média nos indicadores parciais IPOP, IBES e IDE. Enquanto no (IMA) ficou abaixo da média. Isso foi influenciado por duas variáveis: proporção de área ocupada com agricultura familiar e proporção de domicílios com coleta de lixo. O segundo mais alto $\operatorname{IDR}(5,87)$ foi alcançado pelo município de Japonvar, com $63 \%$ da sua população na área rural. Nos indicadores parciais IPOP, IBES e IMA o município apresentou dados acima da média dos demais municípios. Enquanto o IDE ficou abaixo da média. 
A Tabela 5 apresenta a análise descritiva do conjunto de municípios classificados com médio IDR.

Tabela 5 - Análise descritiva dos Municípios com Médio IDR

\begin{tabular}{l|r|r|r|r|r}
\hline & \multicolumn{1}{|l|}{ IPOP } & \multicolumn{1}{|l|}{ IBES } & IDE & \multicolumn{1}{l|}{ IMA } & \multicolumn{1}{l}{ IDR } \\
\hline Valor Máximo & 3,72 & 10,90 & 8,47 & 4,68 & 5,22 \\
\hline Valor Mínimo & 0,22 & 6,49 & 4,83 & 1,06 & 4,52 \\
\hline Média & 1,82 & 9,08 & 5,91 & 2,57 & 4,84 \\
\hline Desvio Padrão & 0,90 & 0,91 & 0,80 & 0,78 & 0,21 \\
\hline Coef.Variação & 0,49 & 0,10 & 0,14 & 0,30 & 0,04 \\
\hline
\end{tabular}

Fonte: Elaboração própria, com base no Censo Agropecuário 2006 e Censo Demográfico 2010

De maneira geral, os municípios que ficaram no nível médio de Desenvolvimento Rural, foram aqueles nos quais, mesmo com níveis baixos em um ou mais indicadores, tiveram outros indicadores elevados que compensaram o cálculo do IDR. Comprova-se pela análise dos valores das dispersões que no cálculo final houve um nivelamento médio entre indicadores parciais, aproximados especialmente pelo IPOP e IMA.

A Tabela 6 apresenta a descrição dos índices referentes aos municípios com baixo IDR.

Tabela 6 - Análise descritiva dos Municípios com Baixo IDR

\begin{tabular}{|c|c|c|c|c|c|}
\hline & IPOP & IBES & IDE & IMA & IDR \\
\hline Valor Máximo & 2,69 & 9,93 & 7,92 & 3,34 & 4,47 \\
\hline Valor Mínimo & 1,38 & 6,18 & 4,35 & 0,72 & 3,68 \\
\hline Média & 0,66 & 8,35 & 5,67 & 2,17 & 4,21 \\
\hline Desvio Padrão & 0,88 & 0,92 & 0,94 & 0,86 & 0,21 \\
\hline Coef.Variação & 1,35 & 0,11 & 0,17 & 0,40 & 0,05 \\
\hline
\end{tabular}

Fonte: Elaboração própria, com base no Censo Agropecuário 2006 e Censo Demográfico 2010

Os municípios classificados com baixo IDR foram aqueles que apresentaram baixos quase todos os indicadores parciais. Os índices que menos contribuíram para a elevação do nível de IDR nesses municípios foram o IPOP e o IMA, conforme pode ser confirmado pelo coeficiente de variação. O município de Itacarambi, com proporção de $22 \%$ de população rural, apresentou o pior IDR, influenciado por todos os indicadores. No indicador de bem-estar, o que mais influenciou foi a variável "Proporção de Domicílios com Abastecimento de Água", em que apenas $12 \%$ da população rural do município possuem esse acesso. No aspecto econômico, as variáveis que mais influenciaram foram a "Proporção de Pessoas Ocupadas", apenas 41\% da população 
rural, e a "renda média per capita rural", que equivale a $70 \%$ da renda média total do município. O aspecto ambiental agrava ainda mais a situação: apenas $30 \%$ dos estabelecimentos rurais do município praticam a conservação do solo, e do total de área rural ocupada, somente $15 \%$ é com agricultura familiar. Com situação semelhante, vêm em seguida Lagoa dos Patos e Curral de Dentro. Esse último chama a atenção por apresentar o indicador de bem-estar acima da média, mas, individualmente, esse indicador não garante a elevação do IDR, pois os demais indicadores são muito baixos.

O Gráfico 1 apresenta o comportamento de cada indicador parcial e do IDR nos municípios da Mesorregião Norte de Minas. Para composição do gráfico, os municípios foram classificados em ordem crescente, conforme o nível de IDR. De forma que, da linha 1 a 23 estão os municípios classificados com baixo IDR, da linha 24 a linha 66 estão os municípios de médio IDR e da linha 67 a 89 os classificados com alto IDR. Alguns indicadores parciais apresentam comportamentos semelhantes entre parte dos municípios que compõem o grupo, como o IDE do grupo de médio IDR e o IBES dos grupos de baixo e alto IDR.

Gráfico 1 - Análise dos Indicadores Parciais e do IDR

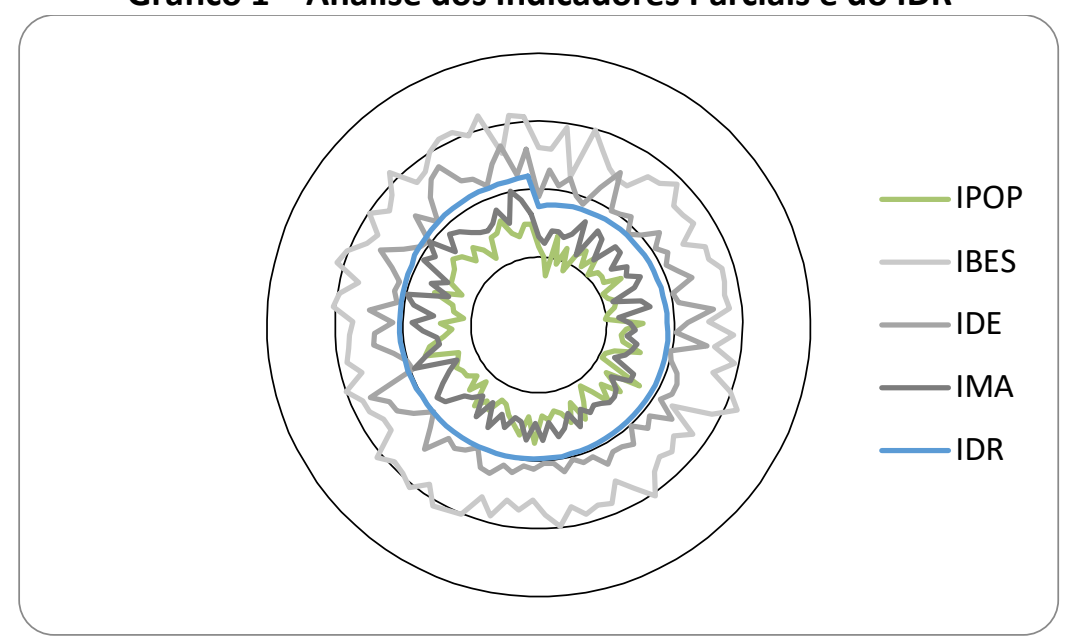

Fonte: Elaboração própria, com base no Censo Agropecuário 2006 e Censo Demográfico 2010

Analisando o comportamento de cada Indicador parcial no gráfico, observa-se certa dispersão entre os municípios. A partir dos dados reforça-se a ideia de que na grande maioria dos municípios há ocorrência de algum tipo de degradação do meio ambiente.

Como antes se ponderou, medir o desenvolvimento rural é complexo. Analisados os grupos, classificados conforme os níveis de IDR, valem algumas 
considerações. Como se constata, o equilíbrio de pesos entre as variáveis pode exercer maior ou menor influência e elevar ou diminuir o índice. Assim é que, aprofundando a análise, observou-se que a maioria dos municípios classificados como alto IDR tem população total menor que 10 mil habitantes. Apenas quatro municípios superam esse número: Jaíba, Taiobeiras, Rio Pardo de Minas e Icaraí de Minas. O percentual de população rural dos municípios de alto IDR apresenta pouca representatividade em relação à população total da Mesorregião, mas com relevante proporção de população rural em relação à população total do município. Já os municípios de maior população total, Montes Claros, Janaúba e Januária, foram classificados no grupo de baixo IDR. Constatou-se que, nos dois primeiros, a população rural em relação à população total é relativamente baixa: 4,83 e 9,33\%, respectivamente.

Numa visão geral, verificou-se que a maioria dos municípios que apresentaram IDR baixo tem uma proporção de população rural significativamente menor em relação à população total. Numa observação mais atenta, contudo, verificou-se que nesse grupo há também municípios com elevada proporção de população rural, tais como: Fruta de Leite $(65,72 \%)$ e Chapada Gaúcha (46,68\%).

A análise mostra, contudo, que não se deve associar o nível de desenvolvimento rural apenas aos aspectos populacionais. Não se pode deixar de comentar que o fato de possuir um número populacional reduzido pode facilitar a implementação de ações que visem o desenvolvimento, e mesmo os resultados delas, no âmbito local. Assim, no grupo de alto IDR, há municípios com reduzido percentual de população em relação à população total, como no caso de Taiobeiras (18,94\%). Por sua vez, o município que apresentou o menor resultado em termos de proporção da população rural foi Pirapora $(1,84 \%)$ e este se inclui no grupo de nível médio IDR. Essas constatações reforçam a ideia de que para melhor nível de desenvolvimento é necessário um equilíbrio entre os aspectos populacionais, sociais, econômicos e ambientais.

\section{CONSIDERAÇÕES FINAIS}

A noção de desenvolvimento rural está ligada a transformações, a mudanças, a melhoria da qualidade de vida da população rural, considerando os aspectos plurais existente nesse meio. No âmbito territorial deve ser considerada a pluriatividade do 
meio rural para que ocorra o desenvolvimento. O desenvolvimento rural resulta de ações articuladas nas vertentes social, econômica e ambiental, com o objetivo de melhorar a qualidade de vida das pessoas. Pode-se dizer que isso ocorre a partir de um processo de evolução que integra a diversidade de ações no âmbito territorial.

Este estudo teve o objetivo de refletir sobre desenvolvimento rural e realizar uma análise empírica da sua medição, aplicada aos municípios da Mesorregião Norte de Minas. O indicador utilizado considera os aspectos populacionais, sociais, econômicos e ambientais. Os resultados contribuíram para reforçar a ideia de que, para buscar o desenvolvimento rural, há uma necessidade de equilíbrio e integração entre as ações implementadas nessas diversas dimensões.

Ao analisar o Indicador Populacional observa-se que a maioria dos municípios da Mesorregião tem apresentado decrescimento da população rural. Essa constatação permite induzir que nesse espaço os atrativos não têm sido suficientes para que a entrada de novos moradores supere a saída de pessoas da área rural. A análise do Indicador de Bem-Estar Social foi discutida com base em variáveis educacionais e de infra-estrutura, trazendo aspectos relevantes para este estudo. $\mathrm{Na}$ análise foi perceptível que a variável referente ao acesso à água apresentou maior variação entre os municípios. Essa constatação não causou surpresa, uma vez que a maioria dos municípios dessa Mesorregião está localizada na região semiárida, caracteristicamente marcada por longos períodos de estiagem. Esse talvez seja o ponto que demande de forma mais urgente políticas públicas que visem amenizar a situação.

No que tange ao Indicador de Desempenho Econômico, esse apresenta diversidade entre os municípios do Norte de Minas. Um aspecto observado nessa análise foi que a população rural dos municípios da Mesorregião tem renda predominantemente menor que a população urbana, numa região em que, de certa maneira, prevalecem as características rurais. Apesar de ter-se trabalhado com rendimento médio mensal não se pode afirmar que todas as pessoas da área pesquisada possuem renda mensal.

Medir a dimensão ambiental no espaço rural não foi uma tarefa fácil. Ainda assim, buscou-se uma análise de indicadores ambientais trazendo uma contribuição para a reflexão sobre o desenvolvimento rural que, mesmo indiretamente, permitissem avaliar a existência de danos e degradações ambientais. Uma das formas de avaliar essa 
dimensão foi considerar que as áreas nos municípios destinadas à agricultura familiar apresentam menores riscos ambientais, com menor utilização de insumos e agrotóxicos. Há décadas observa-se na Mesorregião do Norte de Minas a adoção de modelos de desenvolvimento ligados à modernização agrícola e ao crescimento econômico que não considera as características próprias da região e possibilita a implantação de grandes empresas, responsáveis pelas monoculturas e grandes problemas ambientais. A análise do Indicador de Meio Ambiente demonstrou que a maioria dos municípios da Mesorregião apresentou algum tipo de degradação ambiental.

Em resumo, a análise das dimensões populacionais, de bem-estar social, econômico e meio ambiente trouxe uma leitura da diversidade característica da Mesorregião Norte de Minas, destacando os pontos focais para proposição de ações que visem o desenvolvimento. O agrupamento dessas dimensões possibilitou uma visão dos níveis de desenvolvimento de cada município, tendo em vista a premissa de que para ocorrer o desenvolvimento é preciso um equilibrio, ou seja a combinação de uma série de fatores que caracterizam certa região. Esse equilibrio não se trata de homogeneizar o desenvolvimento dos municípios, mas de associar os fatores que apontam a intensidade do desenvolvimento, considerando os diversos aspectos, além das desigualdades existentes entre os municípios.

A análise do IDR reforçou a ideia de que os aspectos multidimensionais são fundamentais para o desenvolvimento rural e que este não ocorre na mesma intensidade em todos os municípios do Norte de Minas. A análise das dimensões não considerou que uma tem maior ou menor importância que outra dentro do contexto do nível de desenvolvimento. Esse tipo de análise dependeria da atribuição de pesos diferenciados, e não foram encontrados subsídios teóricos que sustentassem a pertinência de se adotar esse procedimento.

A classificação dos municípios segundo o nível de IDR ocorreu em função da média dos indicadores parciais. Os municípios foram organizados em alto, médio e baixo nível de IDR. A maioria dos municípios classificados como alto IDR possuem população total menor que 10 mil habitantes, mas a maioria da população no município está inserida na área rural. De forma geral, os municípios classificados nesse grupo tiveram seus indicadores parciais acima da média e um maior equilíbrio entre os indicadores, sendo que os que mais contribuíram foram os indicadores parciais IPOP, IBES e IMA. Os 
municípios classificados no nível médio de IDR apresentaram um equilíbrio entre os indicadores parciais, aproximados especialmente pelo IPOP e IMA. Já na classificação baixo IDR verificou-se que a maioria dos municípios tem uma proporção de população rural significativamente menor em relação à população total, tendo seus indicadores parciais abaixo da média, apresentando maiores dispersões. Além disso, os indicadores que menos contribuíram para a elevação do nível de IDR nesses municípios foram o IPOP e o IMA.

A ideia de medir o desenvolvimento rural por meio de um indicador possibilitou uma reflexão sobre uma medida que resultasse da combinação de diversas dimensões importantes nesse contexto. Os indicadores calculados fornecem subsídios para compreensão das transformações ocorridas, dadas inclusive, pelas particularidades que envolvem o desenvolvimento da Mesorregião Norte de Minas. Se aplicado ao longo do tempo este estudo pode estabelecer e demonstrar a existência e/ou a persistência das desigualdades no meio rural, sendo uma importante ferramenta para fundamentar a proposição de políticas públicas adequadas à realidade rural de cada região.

Uma medida de desenvolvimento rural que contemple as várias dimensões da área rural exige escolha criteriosa de variáveis e a combinação dessas em cada dimensão, além da observação das características da região a ser analisada. Ainda que tenha sido realizado o esforço de aplicar um modelo de mensuração do desenvolvimento rural neste estudo, é possível ter deixado de se considerar eventuais variáveis relevantes.

Nesse sentido, sugere-se que novos estudos possam contemplar outras variáveis com vistas a aperfeiçoar a análise das singularidades e diversidades próprias do meio rural. Sugere-se ainda, que este estudo seja continuado a partir de análises de correlação entre os índices apresentados e os valores das políticas públicas implementadas em cada município.

\section{REFERÊNCIAS}

ABRAMOVAY, Ricardo. O Futuro das Regiões Rurais. Porto Alegre, Editora da UFRGS, 2003.

BAVA, S.C. Desenvolvimento local: uma alternativa para a crise social? São Paulo em Perspectiva, São Paulo, v.10, n.3, p.53-59, 1996. 
BRASIL. Constituição da República Federativa do Brasil: promulgada em 05 de outubro de 1988, Ed. Atual. São Paulo: Saraiva, 2006.

BRITO, I. C. B.. O reordenamento territorial socioambiental dos geraizeiros em conflito com a monocultura de eucalipto no Norte de Minas Gerais. In: 360 Encontro Anual da ANPOCS, 2012, Águas de Lindóia - SP. 36 Encontro Anual da ANPOCS, 2012.

CARVALHO, José Gilson. Análise da agricultura familiar e do PRONAF no Norte de Minas Gerais [manuscrito] /Universidade Estadual de Montes Claros, 2012.

CONAB, Companhia Nacional de Abastecimento. PAA - Evolução das operações. Disponível em: <http://www.conab.gov.br >. Acesso em 2013

CONTERATO, M. A. ; SCHNEIDER, S.; WAQUIL, P. D.. Desigualdades regionais de desenvolvimento rural do rio grande do sul: uma proposta de análise multidimensional a partir de três microrregiões. 2009. Disponível em: http://revistas.fee.tche.br/index.php/ensaios/article/view/2307/2685. Acesso em 20 de jan de 2014

FAVARETO, A., DEMARCO, D. "Entre o capital social e o bloqueio institucional: uma avaliação dos CMDR em cinco estados brasileiros". In: Schneider, S.; Silva, M. K., Marques, P. E. M. (orgs). Políticas públicas e participação social no Brasil rural. Porto Alegre: Ed. UFRGS, 2004.

FURTADO, C. O mito do desenvolvimento econômico. Rio de Janeiro: Paz e Terra, 1981.

- Desenvolvimento e Subdesenvolvimento. Rio de Janeiro, Contraponto Internacional Celso furtado, 2009.

GIL, Antônio Carlos. Como elaborar projetos de pesquisa. São Paulo: Atlas, 1991. . Capitalismo e moderna teoria social. 5. ed. Lisboa: Presença, 2000. $335 \mathrm{p}$.

GUZMÁN, Eduardo Sevilla. Agroecologia e Desenvolvimento Rural Sustentável. In: AQUINO, Adriana Maria de; ASSIS, Renato Linhares (Eds.). Agroecologia: Princípios e Técnicas para uma Agricultura Orgânica Sustentável. Brasília: Embrapa Informação Tecnológica, 2005. p. 101-32.

GUZMÁN CASADO, G.; GONZÁLEZ de MOLINA, M.; SEVILLA GUZMÁN, E. Introducción a la agroecología como desarrollo rural sostenible. Madrid: Mundi-Prensa, 2000. 535 p.

HELFAND, S. M.; DEL GROSSI, "El Boom Agrícola e la Pobreza Rural en Brasil: 1995- 2006" in Boom Agrícola e Persistencia de la Pobreza Rural en América Latina, edited by J. Graziano da Silva, S. Gomez, and R. Castañeda, Santiago, Chile: UN Food and Agriculture Organization (FAO), 2009.

HELFAND, S. M.; ROCHA, R. VINHAIS, H. E. F. Pobreza e desigualdade de renda no Brasil rural: Uma análise da queda recente. Pesquisa e Planejamento Econômico v. 39 n. 1, abril 2009.

Disponível

IBGE - Instituto Brasileiro de Geografia e Estatística. Censo Agropecuário 2006. em:<http://www.ibge.gov.br/home/estatistica/economia/agropecuaria/censoagro/def ault.shtm>. Acesso em: 30 ago. 2012.

IBGE - Instituto Brasileiro de Geografia e Estatística. Censo Demográfico 2000. Disponível em http://www.ibge.gov.br/home/estatistica/populacao/default_censo_2000.shtm>. Acesso em Jul de 2013 
IBGE - Instituto Brasileiro de Geografia e Estatística. Censo Demográfico 2010. Disponível

http://www.ibge.gov.br/home/estatistica/populacao/censo2010/default.shtm>. Acesso em Jul de 2013

JANUZZI, P. M. Indicadores Sociais no Brasil. Campinas, SP. Ed Alínea, 2012.

KAGEYAMA, A. "Desenvolvimento Rural: conceito e um exemplo de medida". Anais do XLIII Congresso da SOBER Cuiabá (MT). 2004.

MARTINS, Gilberto de Andrade. THEOPHILO, Carlos Renato. Metodologia de Investigação Cientifica para Ciências Sociais Aplicadas. São Paulo. Atlas. 1997.

PUTNAM, Robert D.; LEONARDI, Roberti; NANETTI, Raffaella. Comunidade $e$ democracia: a experiência da Itália moderna. Rio de Janeiro: FGV, 1996. 257 p.

RODRIGUES, Luciene. Formação econômica do Norte de Minas e o período recente. In: OLIVEIRA, M.F., RODRIGUES, L. (Org.). Formação social e econômica do Norte de Minas. Montes Claros: UNIMONTES, 2000.

Itinerário da construção das abordagens de desenvolvimento.

In: Argumentos - Revista do Departamento de Ciências Sociais da Unimontes. Montes Claros: Ed. UNIMONTES, 2009.

SABOURIN, Eric. Camponeses do Brasil: entre a troca mercantil e a reciprocidade. Traduzido do Frances por Leornardo Milani. Rio de Janeiro. Garamond. 2009, 336p.

SARTORI, Giovanni. Comparación Y Método Comparado. 1994. Disponivel em http://pt.scribd.com/doc/53987867/Giovanni-Sartori. Acesso em 06/09/2012.

SCHNEIDER, S.; ELCHER, F.. A Contribuição de Karl Polanyi para a sociologia do desenvolvimento rural. Revista Sociologias, Porto Alegre, ano 13, no 27, mai./ago. 2011, p. $180-219$

SCHNEIDER, S . Território, Ruralidade e Desenvolvimento. In: VELÁSQUEZ LOZANO, Fabio.; MEDINA, Juan Guillermo Ferro (Editores). (Org.). Las Configuraciones de los Territorios Rurales en el Siglo XXI. 1 ed. Bogotá/Colombia: Editorial Pontifícia Universidad Javeriana, 2009, v. 1, p. 67-108.

SEN, Amartya Kumar. Desenvolvimento como liberdade. São Paulo: Companhia das Letras, 2000.

SILVA, Fernanda Faria. Distribuição de crédito para a agricultura familiar: um estudo do PRONAF a partir de um indicador de desenvolvimento rural. Dissertação de Mestrado. Universidade Federal de Uberlândia. 2006.

SILVA, José Graziano da. O Novo Rural Brasileiro, Revista Nova economia. Belo horizonte. 7(1):43-81 (maio de 1997).

SILVA, José Graziano, Jean Marc e Bianchini. O Brasil Rural precisa de uma Estratégia de Desenvolvimento. Brasília: Ministério do Desenvolvimento Agrário / Conselho Nacional de Desenvolvimento Rural Sustentável / Núcleo de Estudos Agrários e Desenvolvimento Rural, 2001.

SILVA, Natália Carolina de Almeida, et al. A Expansão da Monocultura do Eucalipto no Norte de Minas Gerais: Uma abordagem Etnoecológica da Comunidade Cana Brava. Resumos do VI CBA e II CLAA. Revista Brasileira de Agroecologia. Vol. 4 №. 2. Novembro de 2009.

SOUZA, Celina. Estado da Arte da Pesquisa em Políticas Públicas. In: Políticas Públicas no Brasil. HOCHIMAN, Gilberto (org.). Rio de Janeiro. Editora FioCruz. 2007. 398 p. 
SOUZA, M.J.L. O território: sobre espaço e poder, autonomia e desenvolvimento. In: CASTRO, I.E.;GOMES, P.C.C. e CORRÊA, R.L. (Orgs.). Geografia: conceitos e temas. Rio de Janeiro: Bertrand Brasil, 1995.

TONNEAU, J. P.; SABOURIN. E. Agricultura Familiar: interação entre políticas públicas e dinâmicas locais: ensinamentos a partir de casos. Porto Alegre. Editora da UFRGS, 2007.

VEIGA, José Eli da. Desenvolvimento Sustentável: o desafio do Século XXI. Rio de Janeiro. Garamond, 2010. 